\title{
CITRA WANITA DALAM HIKAYAT PEREMPUAN OLEH AMELIA HASHIM (MALAYSIA) DAN ISINGA: ROMAN PAPUA OLEH DOROTHEA ROSA HERLIANY (INDONESIA) BERDASARKAN TEORI KRITIKAN FEMINIS
}

\section{(The Image of Women in the Hikayat Perempuan by Amelia Hashim (Malaysia) and Isinga Roman Papua by Dorothea Rosa Herliany (Indonesia) Based on Feminist Critical Theory)}

Norhayati Ab. Rahman*

yati@um.edu.my

Jabatan Kesusasteraan Melayu, Akademi Pengajian Melayu, Universiti Malaya.

Cahyaningrum Dewojati cahyaningrum@ugm.ac.id

Faculty of Cultural Sciences, Universitas Gadjah Mada.

Corresponding author (Pengarang koresponden): *

To cite this article (Rujukan artikel ini): Norhayati Ab. Rahman \& Cahyaningrum Dewojati. (2021). Citra wanita dalam Hikayat Perempuan oleh Amelia Hashim (Malaysia) dan Isinga: Roman Papua oleh Dorothea Rosa Herliany (Indonesia) berdasarkan Teori Kritikan Feminis. Malay Literature, 34(2), 211-228. http://doi.org. 10.37052/ml34(2)no4

\begin{tabular}{|c|c|c|c|c|c|c|}
\hline $\begin{array}{l}\text { Received: } \\
\text { Peroleh: }\end{array}$ & $30 / 9 / 2021$ & $\begin{array}{l}\text { Revised: } \\
\text { Semakan } \quad-\end{array}$ & $\begin{array}{l}\text { Accepted: } \\
\text { Terima: }\end{array}$ & $28 / / 10 / 2021$ & $\begin{array}{l}\text { Publish online: } \\
\text { Terbit dalam talian: }\end{array}$ & $7 / 12 / 2021$ \\
\hline
\end{tabular}

\section{Abstrak}

Karya sastera oleh pengarang lelaki atau pengarang wanita yang cenderung kepada gaya pengarang lelaki, sering menggambarkan wanita dengan imej wanita yang stereotaip seperti pengalaman wanita dipinggirkan, suara wanita dibisukan, dan bentuk-bentuk paparan yang menyerlahkan male-centredness. Corak penulisan sebegini ialah gambaran penindasan terhadap wanita yang berterusan, sekali gus mencerminkan ciri-ciri stereotaip wanita dalam sastera. Tulisan ini membincangkan novel Hikayat

(C) Dewan Bahasa dan Pustaka. 2021. This work is licensed under the term of the Creative Commons Attribution (CC BY) (http://creative commons.org/licenses/by/4.0/) 
Perempuan dari Malaysia dan Isinga Roman Papua dari Indonesia. Objektif kajian adalah untuk mengenal pasti ciri-ciri stereotaip wanita digambarkan dalam teks kajian, dan menilai sejauh mana ciri-ciri stereotaip mendominasi imej wanita yang dipaparkan. Penilaian tersebut dilakukan dengan menggunakan Teori Kritik Feminis oleh Elaine Showalter. Dapatan kajian menunjukkan sejumlah ciri stereotaip dicitrakan oleh pengarang, sementara selebihnya imej wanita telah keluar daripada stereotaip tersebut. Penemuan ini membuktikan bukan semua pengarang wanita yang terikut-ikut dengan cara mengarang lelaki memaparkan imej wanita yang stereotaip. Sebaliknya terdapat percubaan pengarang wanita untuk meruntuhkan sebahagian ciri-ciri stereotaip wanita tersebut.

Kata kunci: Citra wanita, novel, Malaysia, Indonesia, kritik feminis

\begin{abstract}
Literary works by male or female authors that lean towards the style of male authors often portray women in stereotypical images, such as the marginalization of women's experiences, the silencing of women's voices, and various displays of male-centredness. This type of writing pattern is an illustration of the continuous oppression of women, and thus reflects the stereotypical traits of women in literature. This paper discusses the novels Hikayat Perempuan from Malaysia and Ising a Roman Papua from Indonesia. The objective of this study is to identify the stereotypical traits of women illustrated in the study texts and analyse the extent to which these stereotypical traits dominate the images of women displayed. The analysis is done using the Feminist critical theory by Elaine Showalter. The finding of this study shows that several stereotypical traits are portrayed by the authors, while the remaining images of women have done away with such stereotypes. This finding proves that not all female authors emulate the style of male authors in displaying stereotypical images of women. Conversely, there are attempts by female authors to abolish some of the said stereotypical traits of women.
\end{abstract}

Keywords: Image of women, novel, Malaysia, Indonesia, feminist criticism

\title{
PENDAHULUAN
}

Penulisan ini bertolak daripada kesedaran bahawa karya sastera oleh pengarang lelaki atau pengarang wanita cenderung kepada gaya kepengarangan lelaki, yang sering menggambarkan wanita dengan imej yang stereotaip. Pengalaman wanita dipinggirkan, suara wanita dibisukan dan bentuk-bentuk paparan yang 
hanya menyerlahkan male-centredness. Pembicaraan tentang wanita dalam sastera sering kali menjurus kepada melihat wanita sebagai bahan penceritaan, sama ada oleh pengarang lelaki mahupun wanita. Berdasarkan hasil kajian lepas, pengarang lelaki dikatakan cenderung memberikan gambaran yang tidak tepat mengenai wanita. Gambaran wanita yang dilukiskan oleh lelaki berdasarkan tanggapan, nilai, cita rasa dan pengalaman lelaki, bukan imej sebenar wanita atau berdasarkan pengalaman sebenar mereka. Dalam soal ini, Mary Eagleton memetik pendapat Cynthia Ozick yang dengan sinis menyatakan bahawa wanita muncul dalam penulisan lelaki sebagai "the Muse" - "She is the Muse" - the idealized inspirations for the male writer (1986: 45). Selain Ozick, Mary Ellmann tampil dengan lebih berani melontarkan pendapat bahawa pembinaan wanita oleh pengarang lelaki ialah vicious influence upon writing by men (ibid, p.45). Selain gambaran tentang wanita oleh lelaki yang tidak mewakili keadaan dan pengalaman sebenar wanita, cara penilaiannya pula menggunakan ukur tara daripada teori kritikan lelaki. Teori kritikan lelaki ialah konsep kreativiti sejarah sastera atau interpretasi sastera yang bergantung sepenuhnya pada pengalaman lelaki yang dianggap bersifat universal, yang dihasilkan oleh white father. Menurut Showalter, segala yang dipaparkan dalam penulisan lelaki ialah gambaran penekanan dan penindasan terhadap wanita yang berterusan. Showalter berpendapat, pengarang lelaki tidak berlaku adil kerana mengeksploitasi jasad wanita dalam karya mereka dan mengikut cita rasa sendiri. Malah pemaparan sedemikian juga merupakan suatu bentuk projeksi atau mekanisme bela diri kaum lelaki (1987: 38).

Karya sastera yang digunakan sebagai data bagi penelitian ini ialah novel Hikayat Perempuan (2021) oleh Amelia Hashim dan Isinga: Roman Papua (2015) karya Dorothea Rosa Herliany dengan menggunakan Teori Kritik Feminis oleh Elaine Showalter. Hikayat Perempuan merupakan novel terbaharu pengarang wanita prolifik Amelia Hashim, yang telah menghasilkan puluhan novel terkenal sebelumnya. Hikayat Perempuan ialah novel yang digarap berdasarkan kisah wanita yang terdapat dalam hikayat Melayu seperti yang digambarkan melalui tajuknya. Judul Hikayat Perempuan itu sendiri mencerminkan subjeknya, iaitu tentang kisah perempuan pada zaman silam yang dicitrakan melalui cerita hikayat seperti Hikayat Raja Pasai, Al-Tarikh Salasilah Negeri Kedah, Sejarah Melayu, Hikayat Pattani, Babad Tanah Jawa, Sulalatus Salatin, Tuhfat al-Nafis, Hikayat Banjar, dan Hikayat Hang Tuah. Walaupun kisah yang dipaparkan berkait rapat dengan kehidupan pada zaman silam, namun nilai moral dan didaktik yang dapat ditelusuri pada kisah suka duka wanita pada zaman tersebut tetap sesuai dan relevan untuk sepanjang zaman. 
Novel Isinga Roman Papua (2015) pula ialah novel oleh Dorothea Rosa Herliany yang merupakan pengarang dan penyair terkenal serta prolifik dari Indonesia. Karya ini merupakan pemenang hadiah penghargaan Kusala Sastra Khatulistiwa di Indonesia dalam kategori prosa pada tahun 2015. Novel ini berlatarbelakangkan daerah di Papua, Indonesia. Novel dengan ketebalan 218 halaman ini memaparkan kisah kehidupan masyarakat pedalaman Papua, khususnya di kampung Aitebu dan kampung Hobone yang berbeza budaya dengan masyarakat Jawa atau Sumatera. Mereka digambarkan dengan situasi serba kekurangan, baik dari segi pakaian (sandang), rumah (papan), mahupun makanan (pangan). Percintaan antara dua remaja, iaitu Meage dan Irewa, yang terhalang kerana Malom pemuda dari kampung Hobone telah meminang Irewa. Penolakan pinangan tersebut mencetuskan perang antara dua kampung dan Irewa diculik oleh Malom dari kampung Habone. Mereka kemudian bersetuju untuk berdamai dengan syarat Irewa harus dijadikan sebagai yonime, iaitu juru damai daripada dua adat yang berkonflik. Pada masa yang sama, novel ini menggambarkan wanita etnik Papua yang harus berjuang sendiri bagi menyara keluarganya. Kepercayaan adat telah melestarikan dogma patriarki dan perlakuan diskriminasi yang menjadikan wanita bersifat rendah diri, merugikan, dan hidup sengsara. Permasalahan budaya, sosial, dan isu gender yang dibingkaikan dalam kisah cinta dalam novel ini memperlihatkan kehidupan masyarakat pedalaman Papua Indonesia, khususnya wanita yang diperlakukan secara tidak adil kerana kepentingan adat. Pengarang Dorothea Rosa Herliany menggunakan kata Isinga yang bermaksud "Ibu" dalam bahasa Papua sebagai judul novel untuk dipersembahkan kepada para isinga/isigna/ nisinga (ibu) atau wanita di Papua. Penghayatan terhadap kisah wanita dalam paparan dua buah naratif mewakili Malaysia dan Indonesia ini menarik dalam memperlihatkan citra wanita, di samping dapat dijadikan sebagai sempadan dan teladan berguna kepada pembaca dalam kehidupan pada masa kini.

\section{TEORI KRITIK FEMINIS}

Mary Ellmann dalam buku Thinking About Women (1968) membincangkan pemikiran tentang wanita oleh kebanyakan pengarang lelaki dan mengkritik penampilan serta tanggapan stereotaip mereka terhadap wanita. Teori Kritik Feminis digagaskan oleh Showalter dengan keterangan yang seperti berikut:

It is concerned with the feminist as reader, and it offers feminist readings of texts which consider the images and stereotypes of women in literature, the omissions and misconceptions about women in criticism, and womanas-sign in semiotic systems. (1982, p.12). 
Mod kritikan ini memberi tumpuan kepada wanita sebagai pembaca (woman as reader) atau pengguna teks yang dihasilkan sama ada oleh pengarang lelaki atau wanita yang terikut-ikut dengan cara penulisan lelaki. Marry Ellmann dalam Thinking About Women (1968) membincangkan tentang pemikiran tentang wanita oleh kebanyakan pengarang lelaki dan mengkritik penampilan serta tanggapan stereotaip mereka terhadap wanita. Pendekatan Kritik Feminis disebut juga sebagai feminist reading atau women as reader dengan menumpukan perhatian kepada pemaparan imej dan gambaran wanita stereotaip, pengabaian wanita serta salah tanggapan terhadap wanita dalam kritikan, iaitu berdasarkan sejarah sastera yang ditentukan sepenuhnya oleh lelaki. Secara umumnya wanita dirumuskan dengan ciri-ciri berikut:

1. Formless (tidak berbentuk) merujuk sifat wanita yang dikatakan tidak berpendirian, tidak kukuh dan mudah mengubah pendirian.

2. Unstable (tidak stabil) merujuk sifat wanita yang dikatakan sebagai tidak tetap pendirian dan mudah berubah fikiran, atau mudah dipengaruhi oleh orang lain.

3. Passive (pasif) merujuk sifat wanita yang dikatakan tidak memainkan peranan penting dalam mengawal situasi, atau menggerakkan cerita, sebaliknya hanya berserah kepada keadaan atau orang lain.

4. Confined (tidak berfikiran terbuka) merujuk sifat yang tidak menerima perubahan di sekelilingnya.

5. Pious (warak) merujuk sifat cenderung menyerahkan diri kepada takdir semata-mata, tanpa berusaha untuk berubah atau melawan keadaan.

6. Materialistic (kebendaan) adalah merujuk kepada sifat wanita yang dikatakan mementingkan kebendaan, tidak berfikiran tinggi dan jauh dari sifat intelektual.

7. Spiritual (spiritual) ialah gambaran sifat wanita yang cenderung bergantung pada hal spiritual, bukan kenyataan.

8. Irrational (tidak rasional) merujuk sifat wanita yang melakukan perkara tidak rasional atau tidak munasabah.

9. Compliant (patuh/akur) merujuk sifat wanita yang bersedia untuk mengikut telunjuk orang lain. 
10. Shrew (kuat berleter) merujuk sifat wanita yang dikatakan suka merungut dan cepat marah.

11. Witch (penyihir) merujuk sifat wanita yang boleh memukau dan menyakiti hati orang lain (negatif).

\section{ANALISIS, DAPATAN DAN PERBINCANGAN}

Berdasarkan Teori Kritik Feminis yang dikemukakan oleh Elaine Showalter di atas, didapati sebahagian daripada ciri-ciri stereotaip wanita tersebut adalah selaras dengan gambaran terhadap watak-watak wanita dalam novel Hikayat Perempuan oleh Amelia Hashim dan novel Isinga oleh Dorothea Rosa Herliany. Penyataan tentang ciri stereotaip pertama dalam Teori Kritik Feminis misalnya, gambaran wanita bersifat "tidak berbentuk" (formless) didapati relevan untuk diaplikasi terhadap data kajian ini. Pengaplikasian tersebut adalah relevan dengan cara dan gaya pemaparan watak-watak wanita, terutama watak yang didapati "tidak berbentuk", iaitu merujuk sifat wanita yang dikatakan tidak memiliki pendirian sendiri. Sebagai contoh, ciri tersebut dikenal pasti relevan dengan gambaran pengarang terhadap watak Tun Manda, iaitu puteri kepada Bendahara Seri Nara Diraja, yang semenjak zaman kanakkanak telah "ditunangkan" secara bergurau oleh ayahandanya dengan Pateh Adam, iaitu Pangeran Surabaya, lelaki tua sebaya dengan ayahandanya sendiri. Apabila Tun Manda telah meningkat usia remaja dan menjadi gadis cantik jelita, Pateh Adam datang kembali menuntut janji untuk dikahwinkan dengan Tun Manda. Bendahara Seri Nara Diraja mengerti perasaan anak gadisnya yang tidak suka kepada lelaki tersebut dan menolak pinangannya. Penolakan tersebut menyebabkan berlaku pertarungan antara kedua-dua pihak dan puterinya diancam. Oleh sebab tidak mahu melibatkan campur tangan Sultan dan permusuhan antara Melaka-Majapahit, Bendahara Nara Diraja akhirnya terpaksa menunaikan "janji” akibat gurauan percakapannya dengan Pateh Adam suatu ketika dahulu. Sebagai akibatnya, anak gadis kesayangannya berasa sangat kecewa apabila terpaksa berkahwin dengan lelaki tua tersebut seperti terlihat pada gambaran ini, (2021, p.45).:

Diharapkan ayahnya akan menyelamatkan masa depannya, namun itu tidak terjadi. Dia terpaksa bernikah dan menyerah tubuhnya kepada Pateh Adam yang sudah beruban di kening. Menangis air mata darah sekalipun takdir tidak upaya menukar nasibnya lagi. Selepas bernikah, dia di bawa ke Majapahit sebagai isteri Pateh Adam, entah yang ke berapa. 
Gambaran dalam petikan di atas memperlihatkan harapan Tun Manda yang diungkapkan secara bermonolog agar ayahandanya mampu berusaha menyelamatkan masa depannya. Ironinya, walaupun Tun Manda diperlihatkan sebagai menentang keputusan perkahwinan tersebut, tetapi dia sendiri tidak diberikan suara, pendirian atau keberanian untuk membantah dan menerima sahaja nasib yang telah tertulis oleh gurauan janji ayahandanya sejak beliau masih kecil. Paparan sifat formless pada watak Tun Manda dalam novel ini membenarkan pernyataan bahawa dalam kebanyakan karya pengarang lelaki atau pengarang wanita yang berfikir di bawah pengaruh lelaki, pengalaman wanita dipinggirkan, dan suara wanita dibisukan. Sebaliknya wanita digambarkan secara stereotaip oleh pengarang lelaki sebelumnya (dalam teks dan konteks asal) atau pengarang wanita yang mengikut acuan lelaki.

Corak paparan imej wanita yang "tidak berbentuk" (formless) dalam Hikayat Perempuan di atas, didapati hampir sama pula dengan gambaran terhadap watak wanita etnik Papua dalam novel Isinga di Indonesia. Gambaran dengan sifat "tidak berbentuk" dalam kalangan wanita Papua dalam novel ini diperlihatkan pada tahap kepentingan keberadaan mereka dalam masyarakat. Dalam konteks ini, wanita tidak pernah dilibatkan secara berperanan dalam upacara adat yang dilaksanakan, baik dalam upacara adat keluarga mahu pun upacara penghormatan kepada alam. Dalam konteks masyarakat ini, wanita hanya diperlukan untuk mengurus anak dan menguruskan kerja-kerja rumah tangga. Semua pekerjaan dalam upacara adat dilaksanakan oleh kaum lakilaki. Keadaan tersebut memperlihatkan kedudukan wanita dalam kehidupan bermasyarakat hanyalah di ruangan domestik. Gambaran kehidupan masyarakat yang tinggal di pedalaman Papua, khususnya wanita dikisahkan melalui kehidupan watak Irewa Ongge yang terkongkong dalam sistem sosial dan budaya yang menempatkan wanita sebagai anak, isteri, dan ibu.

Dalam budaya Papua, sifat "tidak berbentuk" wanita dapat dikesan apabila mereka digambarkan sebagai tidak mempunyai pendirian sendiri. Bahkan mereka akur apabila dikahwinkan pada usia yang sangat muda, iaitu setelah mengalami menstrusasi pertama pada usia 12 hingga 14 tahun. Sehubungan dengan itu, diperlihatkan kebanyakan wanita Papua yang menjadi isteri dan ibu sebelum mencapai usia dewasa. Misalnya, dalam Isinga: Roman Papua digambarkan bahawa sebelum mengalami menstruasi pertama, Irewa selalu mendapatkan nasihat daripada Mama Kame agar menjadi wanita yang baik. Nasihat itu disampaikan oleh Mama Kame melalui nyanyian berbahasa Papua yang terlihat pada petikan di bawah ini (2015, p 22): 
Jadilah perempuan yang baik. Perempuan yang baik itu perempuan yang tidak banyak bicara dan tidak pernah marah pada suami. Sebaliknya, perempuan tak baik ialah perempuan yang banyak bicara, sering marah, suka bertengkar dan berkelahi.

Janganlah kau suka iri hati. Iri hati bisa menyebabkan pertengkaran, perseteruan, bahkan pembunuhan.

Gambaran dalam petikan di atas menjelaskan bahawa kehidupan para wanita di Papua masih dikawal dan diatur oleh tradisi. Para wanita Papua yang telah menjadi ibu menasihati anak-anak perempuan mereka dengan nyanyian. Paparan tersebut diperlihatkan melalui watak Mama Kame, iaitu wanita Papua yang telah menjadi seorang ibu. Dia juga memberikan nasihat kepada Irewa agar menjadi wanita yang baik, dengan asas sebagai wanita yang baik ialah wanita yang tidak banyak cakap dan tidak pernah marah kepada suaminya. Kehidupan wanita Papua yang begitu dekat dengan alam menjadikan pandangan masyarakat Papua terhadap nilai wanita yang baik adalah berbeza. Wanita yang lebih banyak bekerja untuk menghidupkan keluarga, namun mereka tidak dibolehkan untuk banyak bercakap, iri hati, atau dengki, yang akan mencetuskan permusuhan malah pembunuhan.

Berdasarkan analisis dan dapatan penelitian di atas, memperlihatkan paparan sifat "tidak berpendirian" atau "tidak berbentuk" pada watak Tun Manda dalam Hikayat Perempuan dan Irewa dalam Isinga: Roman Papua. Pemaparan tersebut membenarkan pernyataan bahawa dalam kebanyakan karya pengarang lelaki atau pengarang wanita yang berfikir di bawah pengaruh lelaki, pengalaman wanita seringkali dipinggirkan, dan suara wanita dibisukan. Sebaliknya wanita digambarkan secara stereotaip seperti yang dinyatakan oleh Teori Kritik Feminis.

Selain itu, pernyataan ciri stereotaip wanita seterusnya ialah bersifat pasif (passive) yang juga dapat dikenal pasti pada kaedah pemaparan watakwatak wanita dalam kedua-dua novel ini. Wanita digambarkan sebagai tidak memainkan peranan penting untuk mengawal situasi, atau menggerakkan cerita, sebaliknya hanya berserah kepada keadaan atau orang lain. Dalam Hikayat Perempuan, gambaran sifat pasif wanita tersebut dapat dikesan pada pemerihalan pengarang tentang watak Tun Kudu, iaitu puteri sulung Bendahara Paduka Wak Raja. Selepas berperasaan bahawa Sultan meminggirkan beliau, berbanding Bendahara Sri Nara Diraja, maka bendahara Paduka Wak Raja berasa dirinya tidak berguna dan telah membunuh diri. Bagi mengurangkan rasa bersalah Sultan, baginda mengahwini Tun Kudu. Namun begitu, apabila tercetus konflik antara Tun Perak dengan Bendahara Sri Nara Diraja, Sultan 
telah menawarkan isteri baginda, Tun Kudu kepada Bendahara Sri Nara Diraja. Sebagai langkah menyelesaikan konflik tersebut, Tun Kudu dilepaskan untuk membolehkannya dikahwini oleh Bendahara Sri Nara Diraja. Dalam konteks cerita ini, Tun Kudu ialah wanita yang dikorbankan untuk tujuan politik, seperti yang dapat dikesan pada ungkapan berikut, (2021: 78):

"Adinda mesti berkorban. Bukan ertinya kanda tidak sayang adinda!"

"Ah, seorang lelaki tiada perasaan!"

"Ini untuk negara!"

"Kenapa cinta dan kasih adinda mesti dikorbankan?"

"Tiada cinta di hati seorang Sultan. Hidup perempuan hanya untuk keperluan!"

Dengan alasan untuk kepentingan negara, Sultan "menawarkan" permaisuri baginda sendiri, untuk diperisterikan oleh orang kanannya itu. Tanpa berupaya untuk membantah atau berbuat apa-apa, Tun Kudu diceraikan dan berkahwin dengan Bendahara Paduka Wak Raja kerana bagi Sultan, "Hidup perempuan hanya untuk keperluan!'. Walaupun tidak bersetuju dengan keputusan tersebut, malah menderita apabila dipaksa berkahwin dengan lelaki tua bernafsu serakah, namun Kudu tidak mampu berbuat apa-apa. Dalam keterpaksaan tersebut, sebagai wanita muda, Tun Kudu melahirkan tiga orang anak dalam masa terdekat. Tun Kudu akhirnya meninggal dunia akibat penderitaan jiwa dan raga, lantaran nafsu serakah suami dan mengenang nasib malangnya yang dicatur oleh kepentingan politik lelaki. Dalam konteks ini, watak Tun Kudu jelas digambarkan sebagai wanita yang tidak berdaya dan tidak dapat mengawal situasi yang dihadapinya. Walaupun caturan hidupnya bertentangan dengan kehendak dan nalurinya sendiri, namun dia hanya terpaksa berserah kepada keadaan atau kehendak orang lain.

Gambaran ciri stereotaip sedemikian juga dapat ditelusuri pada watak wanita dalam novel Isinga: Roman Papua apabila wanita dipaksa supaya bersikap pasif dan akur tanpa membantah atas apa-apa yang ditentukan terhadap diri mereka. Wanita diingatkan supaya tidak banyak bercakap dan hanya akur, kerana sifat tersebut dikatakan dapat melindungi rumah tangga mereka daripada tindakan kekerasan. Misalnya, ketika suami sedang marah, isteri yang baik akan diam dan akur dengan kemarahan si suami sehingga tercipta kedamaian. Penyataan ini dapat dilihat dalam petikan berikut ini (2015: 65-66). 
Perempuan yang baik itu mesti pendiam. Tidak pernah mengeluh. Tidak pernah protes. Tidak pernah membantah. Tidak pernah bersedih. Tidak pernah berbicara kasar. Tidak pernah menyakiti hati orang lain. Tidak suka bertengkar. Tidak pernah marah. Tidak pernah mendendam. Tidak pernah punya perasaan dengki pada orang lain. Senang membantu orang lain. Tidak mengeluh kalau ada kesulitan. Penurut. Tidak pernah bicara kasar. Bersuara lembut. Tidak pernah berkelahi."

Pemaparan dalam petikan di atas memperlihatkan bahawa wanita harus bersikap dalam mendepani kehidupannya, sekali gus untuk memastikan dirinya menjadi wanita yang baik menurut kaca mata masyarakatnya. Pesanan tersebut disampaikan oleh Mama Kame kepada Irewa sebagai persediaan gadis tersebut untuk menjalani kehidupan berkeluarga. Oleh itu, Irewa sentiasa ingat semua sifat dan tindakan yang harus dimilikinya agar menjadi wanita yang baik, iaitu pendiam, tidak pernah mengeluh, tidak pernah protes, tidak berbicara kasar, dan tidak menyakiti orang lain. Jika Irewa memiliki sifat tersebut, masyarakat akan menyukainya. Tuntutan sedemikian melahirkan para wanita yang pasif dan hanya akur mengikut telunjuk orang lain, tanpa bersedia untuk membantah walaupun tidak bersetuju dengan sesuatu ketetapan yang ditentukan atau dipaksakan terhadap diri mereka.

Berdasarkan kaedah pelukisan dan pemerihalan sifat pada watak wanita bernama Tun Kudu dan Irewa dalam kedua-dua teks yang diperkatakan di atas, jelas memperlihatkan pengekalan lakaran imej wanita yang stereotaip, iaitu imej wanita pasif dan patuh-akur seperti yang dinyatakan dalam Teori Kritik Feminis oleh Showalter.

Gambaran imej wanita yang tidak rasional (irrational) yang disebut dalam Teori Kritik Feminis juga dapat diaplikasi pada garapan novel Hikayat Perempuan apabila pengarang melakar watak- wanita dengan sifat dan perlakuan yang tidak rasional atau tidak munasabah. Melalui cerita "Raden Galuh Gemerencang" misalnya, pengarang memaparkan kisah seorang wanita di negeri Pasai yang cantik jelita dan berkeinginan mempertahankan hak untuk memilih sendiri jodoh hidupnya. Dalam usaha untuk mencari sendiri jodohnya, Raden Galuh telah memanggil Tun Perpatih Jena ke istana untuk melukis semua wajah anak raja di benua ini untuk dipilihnya sebagai calon suami. Untuk tujuan itu, Tun Perpatih Jena mengembara selama setahun dan pergi ke seluruh tempat yang mempunyai anak raja. Setelah berhasil melukis wajah sejumlah 100 orang anak raja, dia kembali ke istana. Lukisan ke-100, iaitu wajah Tun Abdul Jalil putera Raja Pasai telah menawan hati Raden Galuh dan ingin segera menikahi anak raja tersebut. Rombongan mereka 
bergerak menuju ke negeri Pasai untuk melangsungkan pernikahan tersebut. Malangnya Ayahanda Tun Abdul Jalil, iaitu Sultan Ahmad Perumal Perumudal telah mengetahui rancangan tersebut dan baginda sendiri berhasrat untuk memiliki Raden Galuh yang cantik jelita. Untuk mencapai kehendak tersebut, puteranya Tun Abdul Jalil dititahkan dibunuh dan mayatnya dibuang ke laut. Berita kematian Tun Abdul Jalil tersebut telah menyebabkan Raden Galuh berasa sangat kecewa, seperti diperlihatkan pada contoh petikan berikut:

"Apa khabar Tun Abdul Jalil?"

"Sudah mati dibunuh, kerana raja itu sendiri mahu mengahwini puteri Raja Majapahit itu!"

“Apa?” jerit Raja Raden Galuh Gemerencang. Suaranya gemersik membelah awan. Menakutkan burung-burung camar. Jeritan kecewa dan marah. Dia menghentak-hentakkan kakinya ke lantai ghurab. "Tidak ada gunanya lagi hidupku di atas dunia ini!" (2020, p.36).

Ungkapan "tidak ada gunanya lagi hidupku di atas dunia ini" dalam petikan di atas membayangkan rasa kekecewaan melampau dalam diri Raden Galuh. Ekoran kekecewaan tersebut, Raden Galuh telah bertindak nekad dengan menenggelamkan kapalnya sendiri untuk mati di lautan dan bersemadi dengan kekasihnya, Tun Abdul Jalil yang mayatnya dibuang ke laut. Pelukisan watak wanita bernama Raden Galuh Gemerencang dalam cerita ini dibaca oleh Teori Kritik Feminis sebagai paparan tindakan wanita yang tidak rasional atau tidak munasabah oleh pengarangnya. Secara logiknya, adalah sangat tidak wajar untuk seorang wanita mengorbankan diri sendiri atas nama kekecewaan atau kerana kebencian. Sebaliknya, tindakan atau strategi yang lebih bijaksana wajar dilaksanakan, yang berkemungkinan boleh menukar situasi yang dihadapi dan berupaya memberi kelebihan lain berbanding memilih kematian. Dengan perkataan lain, wanita sewajarnya digambarkan dengan lebih rasional bagi menentukan tindakan dalam kehidupan mereka.

Melalui novel Isinga: Roman Papua pula diperlihatkan budaya tempatan dalam masyarakat Aitubu Papua yang tidak meletakkan wanita pada posisi yang wajar. Antara lain, wanita dicitrakan bersikap tidak rasional (irrational) kerana tidak diberikan pendidikan sehingga dianggap tidak layak dijadikan pemimpin kelompok atau kepala suku, dukun, atau pergi berburu. Konstruksi budaya di Papua yang berat sebelah terhadap gender membuatkan wanitanya tidak mampu berfikir secara rasional. Contohnya seperti menuntut penceraian, walaupun mereka mengalami penderaan secara fizikal, seksual, dan eksploitasi ekonomi oleh suami, mereka tidak membuat apa-apa tindakan. Melalui novel 
ini, wanita pergunungan Megafu Papua digambarkan tidak pernah berani untuk berpisah daripada suami meskipun suami melakukan kekejaman terhadap diri mereka. Misalnya dalam soal mas kahwin berupa babi yang diterima pihak wanita daripada pihak laki-laki. Mas kahwin yang diterima oleh pihak wanita menandakan bahawa anak perempuan mereka telah dibeli. Pemberian mas kahwin tersebut memberikan hak sepenuhnya kepada laki-laki atas wanita yang telah dijadikan isteri. Bagi pihak wanita pula, mas kahwin yang diterima telah mengikatnya, tanpa dapat menolak kesepakatan kedua-dua belah pihak yang berseteru. Dirinya dijadikan sebagai yonime demi menjaga perdamaian dan mencegah perang antara kedua-dua pihak. Persetujuan tersebut menjadikan Irewa sebagai yonime (jaminan perdamaian bagi kedua-dua pihak yang bertelagah), sekali gus telah merampas kebahagiaannya. Dia bukan saja terpaksa melupakan kekasih hatinya Meage, buat selama-lamanya, malah harus menerima segala perlakuan kasar suaminya. Dalam situasi sedemikian, Irewa dijadikan sebagai wanita yang tidak rasional atas kesanggupannya diperlakukan seperti contoh berikut (2015: 79):

... Irewa sama sekali tak bisa menolak ajakan bersetubuh dari Malom. Sejak itu pula, Malom juga jadi lebih mudah memukul Irewa. Salah sedikit saja, Irewa ditampar atau dipukul. Irewa sering mengingat kata-kata Mama Kame agar ia menjadi istri yang baik. Irewa merasa sungguh tak mudah menjadi istri yang baik.

Berdasarkan petikan data di atas, memperlihatkan wanita digambarkan sudah sebati dengan sifat-sifat tidak rasional dalam kehidupan mereka dalam lingkungan masyarakat yang didominasi oleh lelaki. Walaupun dihentak dengan kekerasan dan ketidakadilan, namun semua itu dianggap sebagai suatu peraturan yang tidak boleh diruntuhkan, hatta wanita sanggup mengorbankan diri sendiri.

Berdasarkan kaedah pelukisan dan pemerihalan sifat watak wanita bernama Raden Galuh Gemercang dan Irewa dalam kedua-dua teks yang dikaji, didapati pelukisan wanita masih kekal dengan imej stereotaip, iaitu tidak rasional. Dengan mengambil tindakan yang tidak munasabah hanya kerana putus harapan atau putus cinta (Hikayat Perempuan) dan kedua dengan membiarkan perlakuan tidak munasabah terhadap dirinya (Isinga: Roman Papua), maka kedua-dua wanita dalam kedua-dua teks ini ternyata cenderung bersifat tidak rasional seperti yang dikemukakan oleh Showalter dalam Teori Kritik Feminis. 
Walau bagaimanapun, didapati bukan semua gambaran wanita dalam kedua-dua novel ini bersesuaian atau bertepatan dengan sifat-sifat stereotaip yang dikemukakan dalam Teori Kritik Feminis. Terdapat sejumlah pemaparan watak-watak wanita yang terkeluar daripada kepompong steretaip. Selain itu, citra wanita yang bertentangan dengan ciri-ciri stereotaip juga dapat dikesan pada sejumlah watak-watak lain. Antaranya, pada bahagian ke-5 dalam novel ini yang memaparkan kisah "Raja Ijau" (Pra' Cau), iaitu puteri kepada Raja Bahadur dari Pattani. Selepas kematian ayahandanya kerana dibunuh, Raja Ijau telah dilantik sebagai Raja Perempuan negeri Pattani, kerana ketiadaan waris lelaki. Negeri Pattani sebelumnya mempunyai waris lelaki, iaitu Sultan Patik Siam, tetapi beliau dan ibunya Raja Aishah telah dibunuh angkara dengki khianat oleh Seri Amar Pahlawan. Tanggungjawab besar yang di bahu Raja Ijau dapat dilihat pada gambaran di bawah:

Selepas dia ditabal sebagai Sultan Pattani, dia berazam mahu selesaikan krisis perebutan kuasa. Raja Ijau tahu pembunuhan kedua-dua sultan ini adalah rancangan Seri Amar Pahlawan. Inilah yang menggoncang perasaan dan fikiran Raja Ijau. Siapa menduga tiba-tiba dibebani dengan tanggungjawab yang maha besar. Belum pernah ada Sultan dalam kalangan wanita, dia yang pertama diyakini akan berjaya mengatasi kemelut gila kuasa itu" (2021: 48).

Paparan petikan di atas memperlihatkan cabaran yang akan dihadapi oleh Raja Ijau sebagai Raja Perempuan yang pertama di Pattani. Naratif seterusnya memaparkan cara, kaedah dan kebijaksanaan Raja Ijau sebagai Raja Perempuan yang memerintah negeri Pattani. Bermula dengan tugas pertamanya menghukum Seri Amar Pahlawan yang telah menyebabkan kematian ayahanda dan sepupunya. Dia juga berjaya membangunkan sistem pengaliran air untuk membantu rakyatnya bercucuk tanam, memperkukuh kekuatan pertahanan dalam usaha menghadapi serangan Siam, dan pada masa sama berhasil mengatasi masalah pemberontakan pembesarnya sendiri. Secara keseluruhannya, cerita ini memaparkan kejayaan Raja Ijau sebagai seorang raja perempuan yang mendepani pelbagai masalah dalaman negeri dan masalah keluarga, tetapi semuanya dapat diatasi dengan baik. Cerita ini jelas menolak ciri-ciri stereotaip wanita, yang dikatakan pasif, akur, tidak rasional seperti yang dicatatkan dalam Teori Kritik Femenis.

Pemerihalan yang sama juga dapat dikesan dalam novel Isinga Roman Papua apabila di sisi lain terdapat pemaparan yang berbeza, yang menyerlahkan superiority wanita. Pada segmen yang lain dalam Isinga Roman Papua dikesan 
kepandaian dan kepentingan peranan kaum wanita di perkampungan Hobone. Kaum wanita di Aitubu diberikan peranan penting dalam penyediaan makanan untuk keluarganya. Ketika kaum lelaki mencari bahan makanan dengan berburu, kaum wanitanya harus mengerjakan kebun. Irewa yang telah berkahwin dengan Malom telah mengikuti suaminya ke perkampungan Hobone. Dia kemudian memahami bahawa sebagai wanita yang tinggal di Hobone, dia harus memiliki kebolehan untuk menyelam dan berkebun bagi memenuhi keperluan makanan (pangan) keluarganya. Selain kawasan hutan yang dapat dijadikan kebun dan ladang, kawasan danau di perkampungan Hobone juga kaya dengan ikan. Para wanita Hobone akan ke Danau Ilmo untuk menangkap ikan bagi keperluan keluarga. Di sini Irewa diajar oleh Mama Fos cara-cara wanita Hobone untuk mendapatkan ikan. Pekerjaan tersebut perlu dilakukan oleh wanita, maka Irewa juga harus mengetahui cara-cara menangkap ikan di danau, iaitu dengan menggunakan jala, menangkap pada malam hari, dan menyelam di dalam air danau. Sebagai wanita Hobone, Irewa harus memiliki kemahiran tersebut sebagai satu keperluan, seperti ungkapan berikut:

\begin{abstract}
"Semua perempuan Hobone bisa menyelam dan kamu juga harus bisa. Sekarang kamu orang Hobone" (2015, p. 60).

Mama Fos Malom memberi tahu bahwa wanita Hobone harus menangkap ikan dengan menggunakan jaring. Jalanya dibuat sendiri dan kalau rusak harus diperbaiki sendiri. Kadang ada juga orang Hobone yang menangkap ikan pada malam hari. Lebih sulit pasti yakni dengan menyelam (2015, p.59-60).
\end{abstract}

Keterangan di atas menjelaskan bahawa tanggungjawab untuk menyediakan makanan bagi keluarga bukanlah pekerjaan mudah yang harus dilakukan oleh kaum wanita. Mereka perlu memainkan peranan penting dan harus bijak mempertaruhkan keselamatan diri dengan memasuki danau tanpa bantuan alat menyelam untuk mencari ikan. Jika tidak mendapat ikan, wanita Hobone, termasuk Irewa harus mengerjakan pekerjaan lain, iaitu memproses pembuatan sagu dan mengurus ladang. Pekerjaan tersebut juga tidaklah mudah kerana jarak ladang yang jauh dan harus melalui perjalanan dengan berperahu. Tanggungjawab yang harus dipenuhi oleh kaum wanita tersebut menunjukkan bahwa ada ketikanya wanita juga digambarkan mempunyai kekuatan tenaga, upaya dan kebolehan yang tidak kalah dengan kaum lelaki.

Berdasarkan analisis di atas, menunjukkan kemampuan dan keupayaan kedua-dua watak wanita, iaitu Raja Ijau (Hikayat Perempuan) melaksanakan 
tugas dan tanggungjawab sebagai raja perempuan. Meskipun baginda terpaksa mendepani pelbagai masalah dalaman negeri dan masalah keluarga, tetapi semua permasalahan tersebut dapat diatasi dengan jayanya. Begitu juga dengan Irewa, yang dari satu sisi digambarkan sebagai bertenaga dan cerdas, berupaya mencari rezeki dengan menangkap ikan dan berkebun, meskipun berdepan dengan pelbagai rintangan. Sifat keperkasaan kedua-dua wanita yang dipaparkan dalam kedua-dua teks ini ternyata menolak ciri-ciri stereotaip wanita, yang digambarkan semata-mata bersifat pasif, akur, tidak rasional seperti yang dicatatkan dalam Teori Kritik Feminis. Sebaliknya, terdapat gambaran wanita seperti watak Raja Ijau yang cekal dan bijak dan watak Irewa yang ada kalanya kuat dan bersemangat dalam kehidupan. Dapatan ini menunjukkan bahawa tidak semua ciri-ciri stereotaip dalam Teori Kritik Feminis dapat disahkan benar berdasarkan dua teks novel yang diperkatakan.

Seterusnya menerusi cerita wanita bernama "Tengku Kamariah" pula membawakan persoalan peranan wanita dalam jatuh bangun politik istana. Tengku Kamariah, anak Sultan Abdul Jalil Riayat Shah pemerintah Johor yang dikahwini oleh Raja Kecik Siak, yang asalnya bertunang dengan kakaknya Tengku Tengah. Tengku Kamariah menyaksikan ayahandanya diturunkan takhta dengan kejam oleh Raja Kecik Siak, lantas baginda memendam rasa marah kepada suaminya. Pemergiannya ke Terengganu untuk bertemu dengan keluarganya tanpa pengetahuan Raja Kecik Siak, menyebabkan suaminya itu telah menghantar orang-orangnya ke Terengganu dan membunuh ayahanda serta membawa Tengku Kamariah kembali ke negeri Siak. Sebagai seorang anak, Tengku Kamariah amat sedih dan marah atas kematian ayahandanya. Perasaannya memberontak dan baginda mendapat keberanian untuk menentang suaminya sendiri. Untuk itu, baginda meminta adiknya Raja Sulaiman agar mendapatkan bantuan daripada Daeng Parani bersaudara untuk menyerang Raja Kecik Siak. Akhirnya Raja Kecik Siak dikalahkan oleh serangan tersebut, yang kemudian menyebabkan baginda menjadi pelarian setelah melarikan diri ke Riau bersama isterinya. Namun Tengku Kamariah tidak menyesal atas takdir tersebut, seperti ujarnya:

Dia bukan isteri yang tidak setia. Suasana politik membalut rasa serba salah. Ditelan racun, diluah melanggar pendirian peribadi. Sebagai wanita dia diasuh ayahnya supaya taatkan suami. Sungguh pedih apabila suami membunuh ayahnya sendiri. Siapa yang tahu kepedihan ini? (2021, p.117).

Dalam konteks di atas Tengku Kamariah digambarkan sebagai wanita yang diberikan keberanian untuk bangkit menentang suaminya yang zalim 
terhadap keluarganya. Malah dia sanggup mengorbankan perasaannya demi menyedarkan suaminya yang bersikap zalim. Pemaparan ini adalah sesuatu yang berbeza daripada keakuran sebelumnya, dan bertentangan dengan ciri-ciri stereotaip pasif dan tidak berpendirian dalam Teori Kritik Feminis. Malah, Tengku Kamariah telah mengambil tindakan yang berani dan penting sehingga meruntuhkan pemerintahan kerajaan suaminya pada ketika itu.

Dalam novel Isinga Roman Papua juga dipaparkan pengalaman hidup Irewa ketika dewasa, yang menjadi kisah yang selalu diceritakan bagi tujuan memberikan motivasi kepada para wanita di sekelilingnya. Walaupun ketika zaman mudanya, beliau digambarkan sebagai seorang wanita yang pasif dan akur dengan nasib dirinya, namun situasi selepas dewasanya adalah berbeza. Perbezaan tersebut dapat dikesan ketika Irewa menghadapi penyakit kelamin lantaran sikap suami yang sering bergaul dengan pelacur yang datang dari luar Papua. Pengalaman buruk tersebut tidak lagi dipendamkan, sebaliknya beliau mula bersuara menyatakan pandangannya. Pengalaman buruk dan malang dirinya itu dikongsikannya kepada para wanita lain supaya dapat dijadikan teladan. Irewa mahu para isteri lebih berhati-hati ketika berhubungan dengan suami mereka, lantaran tidak mahu penyakit yang dialaminya turut menimpa wanita lain. Malah melalui Ibu Selvi Irewa diberikan kepercayaan oleh pejabat Camat Diatrik Yar, iaitu dengan menyediakan ruangan di pejabat tersebut untuk beliau menggerakkan kegiatan para wanita di kampung tersebut. Hal tersebut dilakukan bagi membantu mensosialisasikan dan memberikan informasi tentang penyakit kelamin serta keberadaan penyakit HIV-AIDS kepada anak-anak, remaja, dan juga orang dewasa. Malah Irewa yang pasif sebelumnya, kini dianggap sebagai seorang guru seperti gambaran berikut:

Bicaranya mantap dan menarik bagi semua yang mendengarkan. Si perempuan dari pulau Jawa itu ikut mendukung apa yang dikatakan Irewa bahwa perempuan harus melawan laki-laki. Perempuan lain yang selama ini telah diperlakukan tidak baik oleh suami ikut mendukung. Semuanya jadi saling dukung-mendukung. (2015, p. 158).

Melalui petikan di atas, watak Irewa digambarkan telah mulai bersikap aktif dan dinamik, meskipun wanita tersebut hidup menderita lantaran perbuatan suaminya, kini giat berkongsi pengalaman hidup dan memberi kesedaran kepada kaum wanita di daerahnya. Beliau berharap agar dapat membentuk tanggapan dan cara pandang baharu kepada para wanita yang diperlakukan secara tidak adil, terutamanya oleh suami sendiri. Semangat dan keberanian Irewa menyampaikan pengalamannya ternyata menerima sambutan baik, 
bahkan beliau mendapat sokongan daripara para wanita yang telah diperlakukan secara tidak adil oleh suami mereka. Irewa juga berhasil mengembalikan kepercayaan dalam diri para wanita tersebut sehingga mereka mendapat kekuatan untuk melawan ketidakadilan dan kekejaman yang dilakukan oleh kaum lelaki di daerahnya.

\section{KESIMPULAN}

Berdasarkan perbincangan dan dapatan hasil kajian novel Hikayat Perempuan dan Isinga Roman Papua di atas, dapat dirumuskan bahawa kedua-dua pengarang wanita masih mengarang dalam cara pengarang lelaki. Mereka memaparkan watak wanita yang masih kuat dengan ciri-ciri stereotaip seperti wanita yang bersifat pasif, akur, tidak rasional dan tidak mempunyai pendirian seperti yang dikemukakan dalam Teori Kritik Feminis oleh Elaine Showalter. Watak-watak wanita yang digambarkan sebagai tidak berdaya untuk bertindak, pengalaman mereka tidak dipedulikan, suara mereka dibisukan adalah antara ciri-ciri stereotaip wanita yang masih banyak ditemui dalam kedua-dua novel yang dikaji. Walau bagaimana pun, pada masa yang sama didapati kedua-dua pengarang telah membuat beberapa pembaharuan dalam naratif mereka. Amelia Hashim melalui novel Hikayat Perempuan misalnya, telah merekonstruksi sebahagian watak perempuannya seperti yang dapat dikesan pada watak Tengku Kamariah, dan Raja Ijau. Kedua-dua watak wanita ini tidak membenarkan diri mereka dieksploitasi dan dimanipulasi oleh lelaki atau patriarki. Oleh itu, Raja Ijau diberikan sifat yang kuat, tabah, dan bijaksana untuk melaksanakan tugasnya sebagai pemerintah perempuan. Tengku Kamariah pula diberikan semangat dan keberanian untuk meruntuhkan tembok keangkuhan dan kekuasaan Raja Kecik Siak yang kejam.

Dorothea Rosa Herliany pula menyuntik sifat-sifat berani, prihatin, bersemangat dan berpendirian keapada watak Irewa setelah beliau menjadi wanita dewasa yang memiliki pengalaman buruk sebagai mangsa adat tradisi dan patriarki. Irewa tampil mencabar adat tradisi dan patriarki dengan mendedahkan pengalaman hidupnya yang menjadikannya menderita sebelum ini. Penampilan baharu Irewa bertujuan untuk memberi teladan kepada wanita lain agar tidak menerima nasib malang seperti dirinya. Oleh itu, dapat dirumuskan bahawa sebahagian daripada naratif yang dikemukakan melalui novel Hikayat Perempuan dan Isinga Roman Papua masih menampilkan imej wanita yang stereotaip seperti yang dinyatakan oleh Teori Kritik Femins. Namun begitu, sebahagaiannya pula ternyata telah tampil menyanggah imej stereotaip tersebut, iaitu dengan mengemukakan imej wanita yang positif 
MALAY LITERATURE VOLUME 34 NUMBER 2 DECEMBER 2021

dan aktif, iaitu berani bersuara dan bertindak, bijak, dan berwawasan demi untuk kesejahteraan masyarakat.

\section{RUJUKAN}

Amelia Hashim, (2021). Hikayat perempuan. Dewan Bahasa dan Pustaka.

Christine Campbell. (2004). Contrary visions women and work in Malay novel written by women. Penerbit Universiti Kebangsaan Malaysia.

Dorothea Rosa Herliany, (2015). Isinga: Roman Papua. Cetakan pertama. Gramedia Pustaka Utama.

Ellmann, Mary. (1968). Thinking about women. Mcmillan.

Eagleton, Mary. (ed.). (1986). Feminist literary theory: A reader. 1st Edition.

Humm, Maggie. (1989). The dictionary of feminist theory. Harvester Wheatsheaf.

Lerner, Gerda. (1979). The challenge of women's history, in The majority finds it's past: Placing the women in history. Oxford University Press.

Maggie Humm, (1989). The dictionary of feminist theory. Harvester Wheatsheaf.

Majlis Peperiksaan Malaysia. (2012). Permata sastera Melayu. Dewan Bahasa dan Pustaka.

Norhayati Ab. Rahman, (2020). Pemartabatan Wanita dalam Novel Matriark daripada Perspektif Feminis Cheri Register. Malay Literature Journal, 33(1) 99-122.

Norhayati Ab.Rahman. (2012). Lentera Mustika: Pemartabatan Wanita daripada Lensa Feminis. Jurnal MANU: Jurnal Pusat Penataran Ilmu dan Bahasa, UMS (18):109-130.

Norhayati Ab.Rahman, 2014. Kepengarangan Muslimah Fatimah Busu (Malaysia) dan Titis Basino (Indonesia). PANGSURA: Jurnal Pengkajian dan Penelitian Sastera Asia Tenggara, 32(17), 61-77.

Showalter, Elaine. (1977). A literature of their own. Princeton University Press.

Showalter, Elaine, (1987). Towards a Feminist Poetics. Rick Rylance (Ed.),

Debating texts: A reader in twentieth-century literary theory and methode. Open University Press.

Showalter, Elaine, (1982). Feminist Criticism in the Wilderness. Elizabeth Abel (Ed.), Writing and sexual criticism: Essays on women, literature, and theory. Pantheon. 